\title{
INCOME DISTRIBUTION AND REGIONAL POLICY: THE CASE OF APPALACHIA: COMMENT
}

\section{A. Ray Grimes, Jr.**}

Professors Gunther and Leathers have raised a pertinant issue to be considered by regional development analysts and public policy makers: the existence of significant income inequality within depressed areas and the importance of income redistribution in regional development policy. Their finding is that significant inequality does exist in the distribution of income in Appalachia. However, they do not provide a satisfactory argument for the consideration of redistribution in regional policy planning. Their concern is with the distributional effects of only a single public agency, the Appalachian Regional Commission.

The authors do not establish the compatability of immediate income redistribution with the expressed goal of the act which established the Appalachian Regional Commission whichstates that the goal of ARC is to stimulate "...the development of a diversified economic structure capable of a selfsustaining pattern of growth..."l Many have argued that the relationship between income distribution and economic growth is not at all clear. However, it seems possible that an agency charged with promoting self-sustaining growth would most likely consider income redistribution as a long run consequence of this growth rather than its immediate objective or as an immediate consequence of the pursuit of its assigned goal. In any case, the analysis provided in this paper is conjecture about the "probable" effects of ARC expenditures on income distribution within Appalachia; no attempt has been made to assess the actual effects of the ARC expenditures.

The method used by the authors to assess the possible impact of the distribution of ARC funds on the income distribution in Appalachia is to compute a Gini index of inequality for the Appalachian portion of each state. The most significant weakness of this measure is that it is very insensitive to changes in the distribution of income. However, this is not a problem in the analysis of this paper since the income distribution is only considered at one point in time. Their approach is to compare the rank ordering of the Gini coefficients with the distribution between states of per capita total and nonhighway expenditures by ARC. Their conclusion is that no correlation exists between the allocation of funds and the Gini coefficients. Thus, they conclude that the effect of $A R C$ policies will be at best neutral with respect to the inequality of income in the region.

Even if we felt it a propergoal of ARC to correct, or at least not worsen, the maldistribution of income in Appalachia, I don't believe comparing the income distribution in 1960 with the allocation of expenditures between 1965 and 1970 is adequate for sound judgment. First, no rationale for delineating the region by states was given. The only one that seems apparent is that of expediency--funds are channelled by ARC through state agencies. Certainly one could not assume that the counties of each state constitute a functional economic area. Possibly a more economically rationale grouping would result in a different conclusion. Second, in judging ARC policies, the distribution of social overhead investments, asserted by the authors to have a more positive effect on economic growth than economic overhead investments, should more properly be compared not with the distribution of this one measure (Gini index) but with a set of variables which indicate a subarea's peculiarities and its need for SOI to stimulate self-sustaining econ-

* The author is an Assistant Professor of Economics at the University of Georgia in Athens, Georgia. 
omic growth.

I would mention one other point which I think is probably the most important from the standpoint of assessing the regional development policies of our public development agencies and their effect on the distribution of income within depressed areas. That is the need to consider the policies and expenditures of all agencies concerned with regional development, not just the expenditure pattern of a single agency, particularly one charged not with immediate income redistribution but with providing the foundation for self-sustaining growth. It seems conceivable, and possibly desirable, to have one public agency charged with this objective and another charged with immediate direct income redistribution through income transfers or the provision of public goods and services (for example, OEO). The total effect of these agencies on the income distribution of the region should then be assessed.

I think the authors have made an important contribution by calling attention to the issue of income distribution within depressedareas. They have indicated an intent to look at the change in the income distribution in Appalachia over time to assess the effect of ARC expenditures on the distribution of income. I would encourage them to do so and to consider in their analysis the expenditures of all public developmental agencies not just ARC. Only then can we assess the performance of our regional development policies in attaining a more satisfactory income distribution. Until then substantive conclusions cannot be reached on this important is sue. 


\section{FOOTNOTES}

${ }^{1}$ U.S. Public Law 89-4, Appalachian Regional Development Act of 1965, 89th Congress, March 9, 1965. 